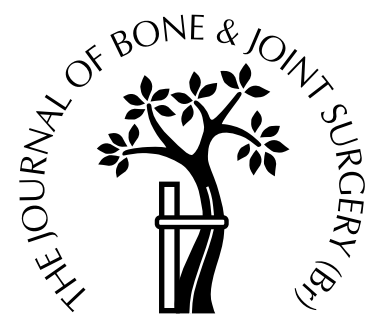

\title{
Synovial osteochondromatosis of the elbow
}

\author{
S. Kamineni, S. W. O’Driscoll, B. F. Morrey \\ From the Mayo Clinic, Rochester, USA
}

$\mathbf{W}$ e present 12 patients with synovial osteochondromatosis of the elbow treated by synovectomy. Histological review showed that seven cases were primary and five secondary osteochondromatosis. The patients with primary disease had a mean improvement in the flexion arc from a preoperative value of $40^{\circ}$ to $123^{\circ}$ to $5^{\circ}$ to $128^{\circ}$ when reviewed at a mean of nine years after operation. The secondary group had a mean improvement in the flexion arc from a preoperative value of $21^{\circ}$ to $98^{\circ}$ to $4^{\circ}$ to $131^{\circ}$ at a mean of 6.8 years after operation. There was recurrence in two of seven patients in the primary group and three of five in the secondary group. Osteoarthritis developed in six elbows in the primary and in three in the secondary group. Osteoarthritis secondary to synovial osteochondromatosis is progressive. In the established condition, the distinction between primary and secondary disease may be of greater histological than clinical relevance.

J Bone Joint Surg [Br] 2002;84-B:961-6.

Received 23 August 2001; Accepted after revision 26 March 2002

Synovial osteochondromatosis is a benign metaplastic proliferative disorder of the synovium ${ }^{1-3}$ which affects subintimal fibroblasts ${ }^{4}$ in synovial joints, ${ }^{5,6}$ tendons and bursae. $^{7}$ It was first described in the knee by Ambrose Paré in $1558^{8}$ and Laennec, in 1813, reported that loose bodies within joints arose from the subsynovial tissues. 9 The synovial origin was confirmed by Brodie although he noted that some arose outside the synovial membrane. ${ }^{10}$

Most cases of synovial osteochondromatosis involve the knee. ${ }^{11}$ A site in the elbow was first reported in 1918 by Henderson, $^{12}$ but any joint may be involved. ${ }^{5,13}$ The few

S. Kamineni, FRCS Orth, Consultant Orthopaedic Surgeon

S. W. O'Driscoll, MD, PhD, Consultant Orthopaedic Surgeon

B. F. Morrey, MD, Professor

Department of Orthopaedic Surgery, Mayo Clinic, 200 First Street Southwest, Rochester, Minnesota 55905, USA

Correspondence should be sent to Professor B. F. Morrey.

(C2002 British Editorial Society of Bone and Joint Surgery 0301-620X/02/712766\$2.00 published accounts of synovial osteochondromatosis in the elbow do little to clarify the condition beyond describing the clinical and operative findings. Reports in the literature range from single cases ${ }^{14,15}$ to a series of 30 patients. ${ }^{16}$ Few describe the clinical outcome. Hence our understanding of the condition affecting the elbow is based on little information.

There are four issues relating specifically to synovial osteochondromatosis in the elbow which require elucidation. These are the incidence of stiffness after surgery and of recurrence, the association between osteochondromatosis and osteoarthritis (OA) and the significance of distinguishing between primary and secondary disease. Based on histological analysis primary synovial osteochondromatosis is characterised by the growth of nodules of cartilage arising de novo by metaplasia of subintimal synovial tissue. Secondary osteochondromatosis has articular hyaline cartilage embedded within loose bodies or in the synovial membrane, ${ }^{17}$ with a recognised underlying aetiology such as degenerative joint disease or osteochondritis dissecans. Our aim was to address these issues and to analyse factors which may influence surgical decisions.

\section{Patients and Methods}

The diagnosis of synovial osteochondromatosis was made in 96 patients between January 1984 and January 1999. Within this same period, loose bodies were removed from 262 elbows. Twelve patients with synovial osteochondromatosis of the elbow were identified and they were reviewed clinically and radiologically.

There were ten males and two females with a mean age at the time of treatment of 39 years (14 to 58). In six patients, the dominant side was affected. The presenting symptom was pain in 11 and there was limitation of movement in seven, of whom six had symptoms of locking or catching and one had a painless contracture. The mean interval between the initial symptoms and the first surgical intervention was six years ( 3 months to 20 years). One patient had an ulnar neuropathy and two had irritable ulnar nerves.

The assessment of the preoperative levels of activity was based on activities which stress the elbow as follows: manual employment and a high-demand recreational life- 


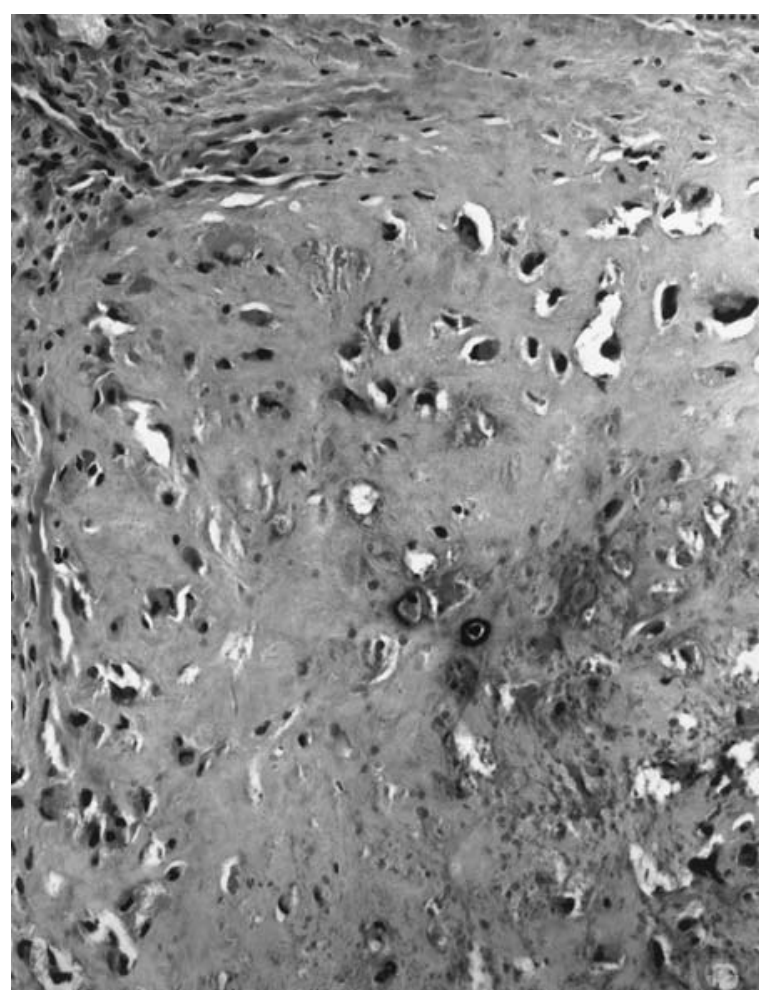

Fig. 1

Photomicrograph of a specimen of primary synovial osteochondromatosis showing a cartilage nodule within synovial tissue. There is cellular atypia, hyperchromasia and powdery calcification (bottom right) (haematoxylin and eosin $\mathrm{x} 35$ ).

style (high, 7); either manual employment or a highdemand recreational lifestyle (medium, 4); and sedentary employment and a low demand recreational lifestyle (low, 1).

In nine patients the preoperative radiographs showed loose bodies in a single compartment in seven and in several compartments in two; four patients were in the primary group and five in the secondary group. Although loose bodies may appear on radiographs to be free, this is often not the case. Synovial attachment commonly confines the loose body to one compartment. Some degree of degenerative joint disease was evident in eight patients. We classified these as severe (loss of joint space with osteophytes) in one, moderate (minimal loss of joint space with anterior and posterior osteophytes) in three, and mild (normal joint space with minimal osteophytes) in four. Surgery consisted of arthroscopic removal of loose bodies in four patients and open removal in eight; subtotal synovectomy was performed in five. Additional procedures included anterior capsulotomy in four, cheilectomy of the olecranon and coronoid in two, humeroulnar arthroplasty in two and transposition of the ulnar nerve in three, in two of whom it was submuscular and in one subcutaneous.

Samples from each patient were sent for histological analysis at the time of surgery and were assessed by a senior orthopaedic pathologist (Fig. 1). The criteria for diagnosing primary disease were: 1 ) the presence of cartilaginous tissue in the synovial membrane; 2) the presence of nodules of chondrocyte nests, with little cartilage matrix separating cells, interspersed in a fibrous matrix; and 3) cellular atypia (hyperchromasia, dumbbell-shaped nuclei and occasional binucleate cells).

All patients were sequentially assessed using the Mayo elbow performance score (MEPS) ${ }^{18}$ and subjective clinical data after a mean of 8.2 years (2 to 15 ).

\section{Results}

Tables I and II give the clinical details, treatment, and final outcome of this heterogenous group. The clinical analysis was based on the histological finding of primary or secondary disease.

Symptoms in the distribution of the ulnar nerve were common with an irritable ulnar nerve in the primary group and neuropathy in the secondary group. Relief from pain was one of the principal goals for surgery. Those patients with primary osteochondromatosis had a mean improvement in the pain score from 17 (15 to 30 ) to 41 (30 to 45). In five patients with secondary osteochondromatosis there was a mean improvement in the pain score from 21 (0 to 45) to 42 (30 to 45$)$.

The movement in the primary group improved from a mean preoperative range of flexion of $40^{\circ}$ to $123^{\circ}$ and pronation/supination of $83^{\circ}$ to $78^{\circ}$ to a mean postoperative range of flexion of $11^{\circ}$ to $119^{\circ}$ and pronation/supination of $90^{\circ}$ to $73^{\circ}$. However, one patient in the primary group (case 4) represented a very atypical situation in which there were many confounding factors which adversely affected the function of the elbow including four previous treatments with radiation. When this patient was excluded from the analysis, the mean postoperative range of flexion improved to $5^{\circ}$ to $128^{\circ}$ and pronation/supination to $90^{\circ}$ to $77^{\circ}$. The movement in the secondary group improved from a mean preoperative range of flexion of $21^{\circ}$ to $98^{\circ}$ and pronation/ supination of $82^{\circ}$ to $90^{\circ}$, to a mean postoperative flexion of $4^{\circ}$ to $131^{\circ}$ and pronation/supination of $82^{\circ}$ to $80^{\circ}$ at final review, representing a change from 16 points to 25 points on the functional score. The overall MEPS was similar in the two groups with an increase from 57 points to 94 points for the primary group and from 64 points to 97 points for the secondary group.

Five patients had recurrence of symptoms; in three further surgical treatment was required and two declined further intervention. The symptoms of recurrence were similar to those which occurred before the previous surgery and the diagnosis was confirmed on radiography. Of the two who declined further intervention, in one (secondary group, case 5) the histological diagnosis was secondary synovial chondromatosis. He had a recurrence at five years with slightly less pain in the elbow with the re-formation of loose bodies. He received conservative treatment and was 
Table I. Details of the patients with synovial osteochondromatosis of the elbow and their treatment

\begin{tabular}{|c|c|c|c|c|c|c|c|c|c|c|}
\hline Case & $\begin{array}{l}\text { Age } \\
\text { (yrs) }\end{array}$ & Gender & $\begin{array}{l}\text { Dom/ } \\
\text { nondom* }\end{array}$ & Presentation & Activity & Interval $\dagger$ & $\begin{array}{l}\text { Pe E-F; P-S } \ddagger \\
\text { (degrees) }\end{array}$ & $\begin{array}{l}\text { Radiographs§ } \\
\text { (initial) }\end{array}$ & Operation $\mathbb{I}$ & Histology** \\
\hline \multicolumn{11}{|c|}{ Primary } \\
\hline 1 & 54 & M & Dom (R) & $\begin{array}{l}\text { Pain, catching, } \\
\text { ROM }\end{array}$ & Medium & 8 yrs & $50-120 ; 70-70$ & $\begin{array}{l}\text { Early OA (olecranon + } \\
\text { coronoid spurs), LBs }\end{array}$ & $\begin{array}{l}\text { Olecranon + coronoid debridement, LBs } \\
\text { removed, ant capsulotomy, little OA }\end{array}$ & PSC \\
\hline 2 & 29 & $\mathrm{~F}$ & Dom (R) & $\begin{array}{l}\text { Painful_ROM after } \\
\text { activity }\end{array}$ & Medium & $2 \mathrm{yrs}$ & $55-115 ; 90-90$ & Early OA & $\begin{array}{l}1 \text { LB removed, subtotal synovectomy } \\
\text { (arthroscopic), with anterior capsular } \\
\text { release }\end{array}$ & PSC \\
\hline 3 & 44 & M & $\begin{array}{l}\text { Nondom } \\
\text { (L) }\end{array}$ & $\begin{array}{l}\text { Discomfort, reduced } \\
\text { extension, catching }\end{array}$ & High & $7 \mathrm{yrs}$ & $20-135 ; 90-90$ & $\begin{array}{l}\text { Ectopic bone posteriorly } \\
+ \text { medially, early OA }\end{array}$ & Arthroscopic removal LBs, little OA & PSC \\
\hline 4 & 38 & M & Dom (R) & $\begin{array}{l}\text { Stiff, painful elbow; } \\
\text { irritable ulnar nerve }\end{array}$ & Low & 18 mths & $90-100 ; 70-70$ & $\begin{array}{l}\text { Unusual distribution } \\
\text { osteoporosis, severe OA, } \\
\text { heterotopic ossifications }\end{array}$ & $\begin{array}{l}\text { Open synovectomy, circumferential } \\
\text { capsulotomy, olecranon + coronoid } \\
\text { cheilectomy, subcutaneous transposition } \\
\text { UN, distraction arthroplasty }\end{array}$ & PSC \\
\hline 5 & 41 & M & Dom (R) & Painful_ROM & Medium & $5 \mathrm{yrs}$ & $20-130 ; 90-90$ & Moderate OA, anterior LBs & Open LB removal and HUA & PSC \\
\hline 6 & 22 & M & Dom (R) & Painful locking & High & $8 \mathrm{mths}$ & $15-135 ; 80-45$ & No $\mathrm{OA}$ and one $\mathrm{LB}$ & $\begin{array}{l}\text { Arthroscopic LBs removal, } \\
\text { chondromalacia of radial head }\end{array}$ & PSC \\
\hline 7 & 54 & $\mathrm{~F}$ & $\begin{array}{l}\text { Nondom } \\
\text { (L) }\end{array}$ & $\begin{array}{l}10 \text { yrs of pain, } \\
\text { locking,_ROM }\end{array}$ & Medium & $10 \mathrm{yrs}$ & $35-130 ; 90-90$ & $\begin{array}{l}\text { Multiple anterior LBs, } \\
\text { small proximal ulnar } \\
\text { osteophytes, early OA }\end{array}$ & $\begin{array}{l}\text { Arthroscopic LBs removal (15) from } \\
\text { anterior and posterior compartments } \\
\text { and synovectomy of affected areas (3) }\end{array}$ & PSC \\
\hline \multicolumn{11}{|c|}{ Secondary } \\
\hline 1 & 58 & M & Dom (R) & $\begin{array}{l}\text { Irritable ulnar } \\
\text { nerve, pain }\end{array}$ & High & $15 \mathrm{yrs}$ & $10-45 ; 90-90$ & $\begin{array}{l}\text { Multiple LBs, } \\
\text { moderate OA }\end{array}$ & $\begin{array}{l}\text { Open arthrotomy + LBs removal, } \\
\text { submuscular transposition UN }\end{array}$ & LBs \\
\hline 2 & 18 & M & $\begin{array}{l}\text { Nondom } \\
\text { (L) }\end{array}$ & Painful catching & High & $2 \mathrm{yrs}$ & $10-120 ; 90-90$ & $4 \times$ LBs, no OA & $\begin{array}{l}\text { Arthroscopic multiple LBs removal, } \\
\text { synovectomy, coronoid }+ \text { olecranon } \\
\text { cheilectomy, possible associated OCD }\end{array}$ & LBs \\
\hline 3 & 45 & M & $\begin{array}{l}\text { Nondom } \\
\text { (L) }\end{array}$ & $\begin{array}{l}\text { Painful_ROM in } \\
\text { extension, locking }\end{array}$ & High & $8 \mathrm{yrs}$ & $40-90 ; 90-75$ & $\begin{array}{l}\text { Multiple anterior } \mathrm{LBs} \text {, } \\
\text { early OA }\end{array}$ & Open LBs removal & LBs \\
\hline 4 & 14 & M & $\begin{array}{l}\text { Nondom } \\
\text { (L) }\end{array}$ & Painless_ROM & High & $3 \mathrm{mths}$ & $15-120 ; 80-70$ & No OA, LBs & Open LBs removal & LBs \\
\hline 5 & 51 & M & $\begin{array}{l}\text { Nondom } \\
\text { (L) }\end{array}$ & $\begin{array}{l}\text { Ulnar neuropathy, } \\
\text { and elbow pain }\end{array}$ & High & $20 \mathrm{yrs}$ & $30-115 ; 60-65$ & $\begin{array}{l}\text { Few LBs mostly posterior } \\
\text { compartment, moderate OA }\end{array}$ & $\begin{array}{l}\text { Open LBs removal, HUA, } \\
\text { subcutaneous transposition UN }\end{array}$ & LBs \\
\hline
\end{tabular}

*dominant/non-dominant

$\dagger$ interval between first symptoms to first surgery

$\$$ Pe, preoperative; E, extension; F, flexion; $\mathrm{P}$, pronation; $\mathrm{S}$, supination

\&LBs, loose bodies

IUN, ulnar nerve; OCD, osteochondritis dissecans; HUA, humeroulnar arthroplasty

**PSC, primary synovial osteochondromatosis

Table II. Outcome in the 12 patients with synovial osteochondromatosis of the elbow

\begin{tabular}{|c|c|c|c|c|c|c|c|c|c|}
\hline Case & $\begin{array}{l}\text { Po E-F; P-S* } \\
\text { (degrees) }\end{array}$ & Recurrence $\dagger$ & Revision surgery $\neq$ & $\begin{array}{l}\text { FU§ } \\
(\mathbf{y r s})\end{array}$ & FU-F; E; P; S & Pain & Motion & Function & Comments I \\
\hline \multicolumn{10}{|c|}{ Primary } \\
\hline 1 & $0-135 ; 70-50$ & Nil & Nil & 8 & $0-135 ; 90-10$ & $15-45$ & $15-20$ & $20-25$ & Brother with SOC knee \\
\hline 2 & $15-130 ; 80-80$ & $37 \mathrm{mths}+7 \mathrm{yrs}$ & $\begin{array}{l}\text { Open synovectomy, } \\
\text { large mass removed, } \\
\text { anterior capsular } \\
\text { release }\end{array}$ & 15 & $0-130 ; 90-90$ & $15-45$ & $15-20$ & $15-25$ & $\begin{array}{l}\text { Had } 2 \text { arthroscopic debridements before surgery at } \\
\text { our institution. Posterior femoral exostosis removed } \\
\text { aged } 15 \text { yrs. Father had knee replacement due } \\
\text { to severe OA }\end{array}$ \\
\hline 3 & $5-130 ; 90-90$ & Nil & Nil & 10 & $20-100 ; 90-90$ & $15-30$ & $20-20$ & $10-25$ & \\
\hline 4 & $35-110 ; 90-70$ & $18 \mathrm{mths}$ & Nil & 3 & $45-65 ; 90-55$ & $15-30$ & $15-15$ & $10-20$ & $\begin{array}{l}\text { Had } 4 \text { previous open procedures, } 4 \text { previous } \\
\text { radiotherapy sessions and aggressive physiotherapy }\end{array}$ \\
\hline 5 & $5-135 ; 90-90$ & Nil & Nil & 12 & $5-135 ; 90-90$ & $15-45$ & $20-20$ & $15-25$ & Previous cortisone injections; physiotherapy \\
\hline 6 & $0-145 ; 90-90$ & Nil & Nil & 2 & $0-130 ; 90-90$ & $30-45$ & $20-20$ & $10-25$ & \\
\hline 7 & $5-130 ; 90-90$ & Nil & Nil & 8 & $5-140 ; 90-90$ & $15-45$ & $15-20$ & $15-25$ & Family history of rheumatoid arthritis \\
\hline \multicolumn{10}{|c|}{ Secondary } \\
\hline 1 & $0-140 ; 80-80$ & $1 \mathrm{yr}$ & TEA & 15 & $0-140 ; 80-80$ & $15-45$ & $15-20$ & $15-25$ & \\
\hline 2 & $5-125 ; 90-90$ & Nil & Nil & 3 & $0-130 ; 90-90$ & $30-45$ & $20-20$ & $15-25$ & \\
\hline 3 & $20-135 ; 70-80$ & $1 \mathrm{yr}$ & $\begin{array}{l}\text { Open removal of } \\
\text { LBs, HUA, radial } \\
\text { head resection }\end{array}$ & 6 & $5-130 ; 90-90$ & $15-45$ & $15-20$ & $15-25$ & $\begin{array}{l}\text { Sister and niece both had exostoses removed from } \\
\text { proximal humerus }\end{array}$ \\
\hline 4 & $25-135 ; 80-70$ & Nil & Nil & 2 & $5-135 ; 90-80$ & $45-45$ & $20-20$ & $20-25$ & Postoperative superficial nerve palsy (recovered) \\
\hline 5 & $25-120 ; 75-80$ & 5 yrs & Nil & 8 & $10-120 ; 60-60$ & $0-30$ & $15-20$ & $15-25$ & \\
\hline
\end{tabular}

*Po, postoperative; E, extension; $\mathrm{F}$, flexion; $\mathrm{P}$, pronation; $\mathrm{S}$, supination

$\dagger$ from therapeutic surgery to recurrent symptoms

¥TEA, total elbow arthroplasty; LBs, loose bodies; HUA, humeroulnar arthroplasty

$\S \mathrm{FU}$, follow-up from surgery to final review

ISOC, synovial osteochondromatosis 


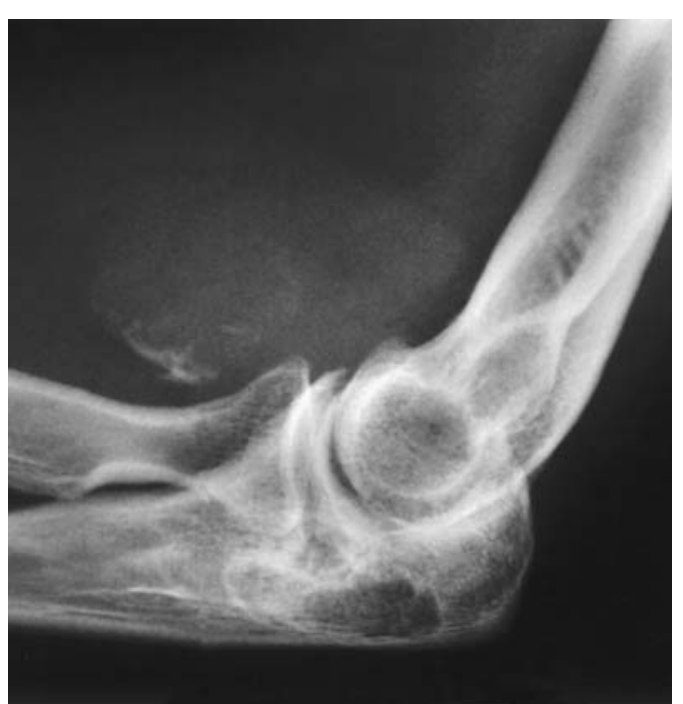

Fig. 2a

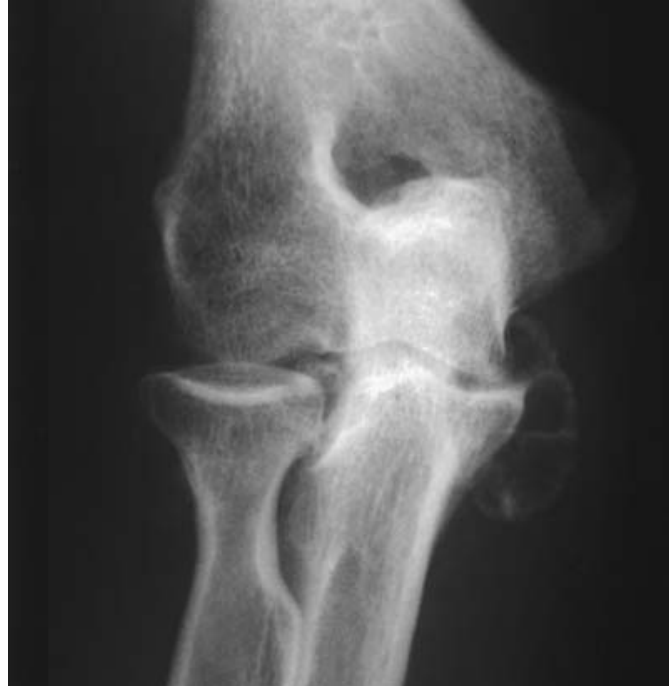

Fig. $2 b$

Case 2 (primary group). Lateral (a) and anteroposterior (b) radiographs 37 months after operation showing recurrence and mild OA.

able to resume manual employment. The second patient (primary group, case 4) was from overseas and had had multiple operations before his treatment at our institution, including open debridement, radiation therapy and intensive physiotherapy. Severe intra- and extra-articular adhesion and scarring were noted at operation and the chondral surfaces had undergone widespread stage-II and stage-III degenerative changes. After removal of the loose bodies and total synovectomy, a circumferential capsulotomy was performed. Stiffness and pain recurred, but his symptoms were an improvement on the preoperative state and he was unwilling to consider further intervention.

Of the three patients who were operated on for recurrent symptoms, the histological diagnosis was secondary disease in two (secondary group, cases 1 and 3) and primary disease in one (primary group, case 2). The former two underwent total elbow arthroplasty (case 1) and debridement, humeroulnar arthroplasty and resection of the radial head (case 3). The third patient had two recurrences after initial surgery at another hospital, and two further recurrences after surgery at our institution. The elbow was debrided again when the symptoms became unmanageable by conservative measures and an anterior capsulotomy was performed. At the initial presentation no loose bodies had been visible on plain radiography, but a single loose body was removed from the lateral gutter, and a pedunculated partially calcified body was evident at recurrence (Fig. 2).

Before surgery, osteoarthritic changes were severe in one patient, moderate in three, and mild in five. At final review there was one case of severe, three of moderate, and four of mild OA. One of the patients with moderate OA had a total elbow arthroplasty because of rapid symptomatic progression and intraoperative findings of significant chondral destruction (secondary group, case 1). The patients with
OA in the primary group showed no deterioration from the time of surgery to the final follow-up, whereas in the secondary group, one progressed from mild to moderate OA in spite of a further debridement (secondary group, case 3 ).

\section{Discussion}

A review of the literature on primary synovial osteochondromatosis highlights two issues first, that the definition and criteria by which the diagnosis is made, are unclear, and secondly, that little is known about this disorder. Clinically, the symptoms and signs are not specific and may suggest several differential diagnoses. The clinical presentation is commonly of pain, mechanical symptoms, and/ or loss of movement, none of which is specific. Pain may follow exertion but may also be due to effusion, locking, nerve compression or secondary osteoarthritic changes. ${ }^{19,20}$ The inability fully to extend the elbow was thought to be the first significant symptom ${ }^{21}$ followed by catching and locking. ${ }^{1}$ Stiffness of the elbow is not a characteristic feature of the primary condition. All 12 patients in our study had a reduced range of extension $>10^{\circ}$ with a mean of $40^{\circ}$ ( 15 to 55 ) in the primary group (with the exclusion of case 4 for reasons of multiple confounding features), and $21^{\circ}$ (10 to 40$)$ in the secondary group. Whereas the primary group mostly had an extension deficit, the secondary group had less extension deficit and greater flexion deficit. In both groups, however, the deficits were amenable to surgical release. Symptoms in the ulnar nerve have been reported twice. $^{15,22}$ Our findings serve to highlight that spontaneous symptoms in the ulnar nerve can be caused by either primary or secondary synovial osteochondromatosis due to pressure from swelling or as part of a contracture. 


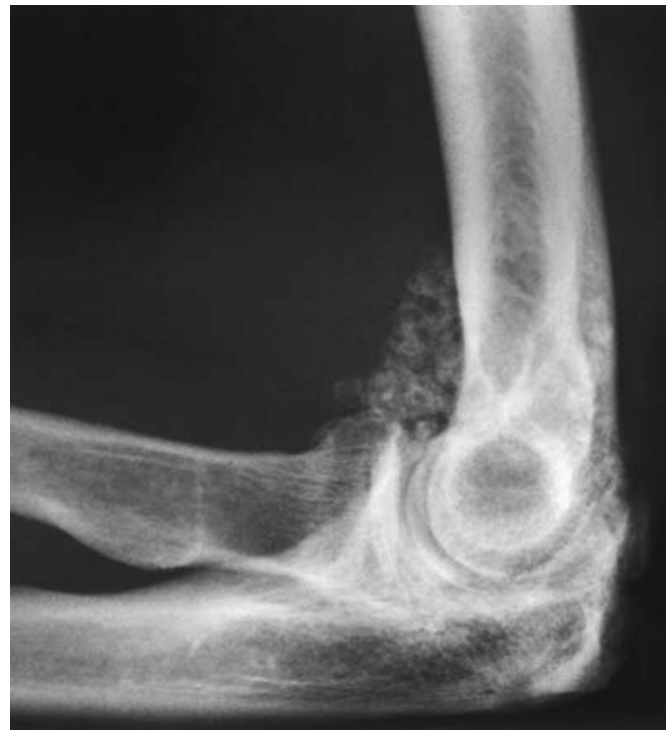

Fig. 3

Case 5 (primary group). Lateral radiograph showing a typical appearance of synovial osteochondromatosis with fine speckled calcifications.

Plain radiographs are said to reveal that between $66 \%{ }^{6}$ and $80 \%$ of all loose bodies are caused by synovial chondromatosis. In our series five of the seven primary patients had radiologically visible lesions. Some degree of calcification of cartilage is present in $60 \%$ and ossification in $55 \%$ of cases. ${ }^{24}$ Not all radiographs show the typical appearances of primary synovial chondromatosis (Figs 3 and 4) and some serve to confuse between the primary and secondary conditions (Fig. 5). Ultrasonography has demonstrated lesions which were not detected on plain radiographs, ${ }^{25}$ as has arthrography, CT and arthro-CT scanning. ${ }^{26}$

Both operative and non-operative treatments have been described for the management of synovial osteochondromatosis. Relief from pain has been reported with conservative management. A non-surgical approach has also been advocated for the disease in phases II and III, ${ }^{27,28}$ with the latter authors recommending any necessary treatment when the disease has become quiescent, suggesting an improved outcome. ${ }^{17}$ However, most authorities recommend surgery, although the extent of the intervention varies. ${ }^{19,20,22}$ Recurrence after removal of an isolated loose body has led some authors to advise adjunctive synovectomy for all cases. ${ }^{11}$ Whereas most published studies recommend synovectomy in some form, its value has been questioned in the light of reports showing no differences in outcome after debridement and synovectomy. ${ }^{16}$ Our experience also suggests that extensive synovectomy is not always necessary for inactive disease since four patients in the primary group were treated successfully by debridement alone. This allows a more selective use of adjunctive synovectomy, particularly when the histological findings indicate an active pathological process.

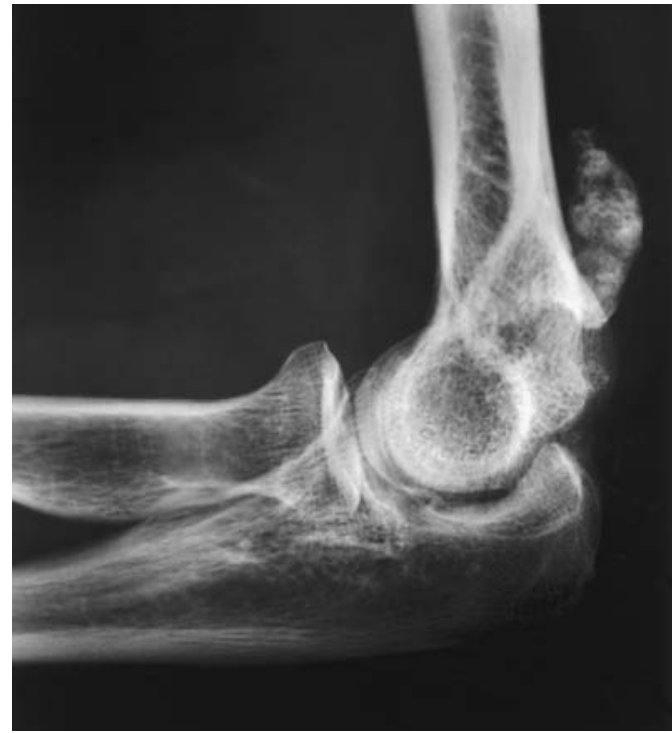

Fig. 4

Case 3 (primary group). Lateral radiograph showing a less typical appearance of primary synovial osteochondromatosis.

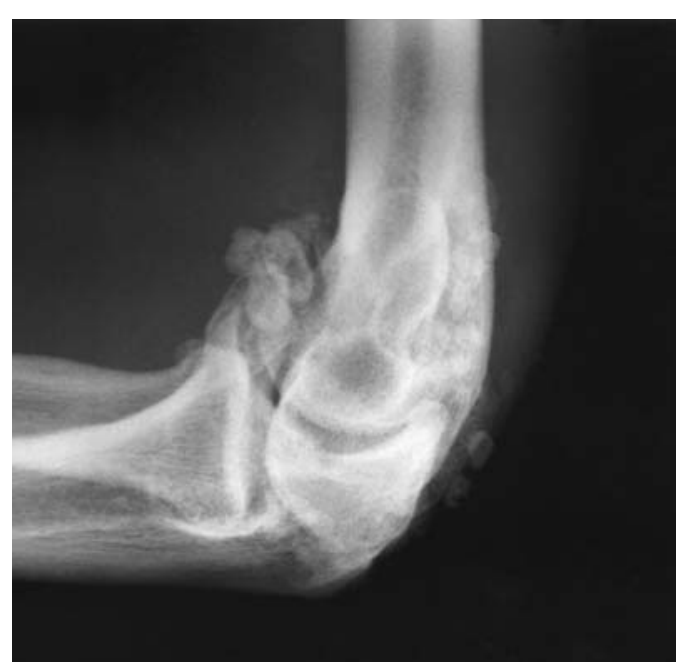

Fig. 5

Case 3 (secondary group). Lateral radiograph showing loose bodies secondary to degenerative joint disease.

The reported incidence of recurrence is between $0 \%{ }^{21}$ and $22 \%{ }^{23}$ The cause is usually assumed to be incomplete removal of loose bodies and/or diseased synovium. The true incidence of recurrence, however, is as uncertain as the initial diagnosis with respect to the symptoms of recurrence compared with the symptoms at initial presentation. If the cause is truly the incomplete removal of pathological tissue, it is difficult to explain the recurrence in case 2 (primary group) in which at this site a repeated subtotal synovectomy had been carried out and yet there were two further recurrencies (Fig. 2). Recurrence has also been linked to high levels of physical 
activity, ${ }^{13}$ but two patients in our series with recurrent disease were not particularly active.

The association between synovial chondromatosis and OA has been reported as either non-existent ${ }^{17}$ or rare. ${ }^{24}$ Our observations suggest a common pathway for all loose bodies as an aetiology for degenerative change. Of those patients with a recurrence who underwent further surgery, the stage of OA remained unchanged. Patients presenting at longer intervals had a more advanced stage of OA, but this also remained relatively unchanged at the final follow-up. Our findings suggest that repetitive synovectomy and removal of loose bodies may delay the progression of degenerative changes, which corroborates the findings of Gilbert and Lachiewicz. ${ }^{27}$

From our study we deduce that the histological distinction between the primary and secondary diseases adds little to our understanding of stiffness, recurrence, and secondary OA since they behave similarly. Stiffness associated with primary and secondary synovial osteochondromatosis responds well to surgery, especially with regard to restoring extension. Primary synovial osteochondromatosis can recur after subtotal synovectomy and recurrence may be associated with surgical intervention at an earlier, more active, stage in the process of the disease. OA secondary to synovial osteochondromatosis appears to progress, but in early primary disease does not appear to progress beyond the stage at which definitive surgery is performed.

No benefits in any form have been received or will be received from a commercial party related directly or indirectly to the subject of this article.

\section{References}

1. Henderson MS, Jones HT. Loose bodies in joints and bursae due to synovial osteochondromatosis. J Bone Joint Surg 1923;5:400-9.

2. Apte S, Athanasou NA. An immunohistological study of cartilage and synovium in primary synovial chondromatosis. $J$ Pathol 1992;166:277-81.

3. Freund E. Chondrosacromas of the joints. Arch Surg 1937;34:670.

4. Wilson WJ, Parr TJ. Synovial chondromatosis. Orthopedics 1988;11:1179-83.

5. Milgram JW. Synovial osteochondromatosis: a histopathological study of thirty cases. J Bone Joint Surg [Am] 1977;59-A:792-801.
6. Murphy FP, Dahlin DC, Sullivan CR. Articular synovial chondromatosis. J Bone Joint Surg [Am] 1962;44-A:77-86.

7. Matsumoto K, Hukuda S, Fujita M, Kakimoto A, Tachibana S. Cubital bursitis caused by localized synovial chondromatosis of the elbow: a case report. J Bone Joint Surg [Am] 1996;78-A:275-7.

8. Barwell R. Movable bodies in joints. Brit Med J 1976;I:184-6.

9. Halstead AE. Floating bodies in joints. Ann Surg 1895;Xxii:327-42.

10. Marsh FH. Notes suggested by some of the specimens that have been added to the museum in the course of the year. St Barth Hosp Rep 1868;Iv:248-58.

11. Ogilvie-Harris DJ, Saleh K. Generalized synovial chondromatosis of the knee: a comparison of removal of the loose bodies alone with arthroscopic synovectomy. Arthroscopy 1994;10:166-70.

12. Henderson MS. Loose bodies in the elbow joint. $J$ Am Med Assoc 1918;xxi:177-80.

13. Mussey RD Jr, Henderson MS. Osteochondromatosis. J Bone Joint Surg [Äm] 1949;31-A:619-27.

14. Milgram JW, Pease CN. Synovial chondromatosis in a young child: a case report. J Bone Joint Surg [Am] 1980;62-A:1021-3.

15. Ruth RM, Groves RJ. Synovial chondromatosis of the elbow presenting with ulnar nerve neuropathy. Am J Orthop 1996;25:843-4.

16. Shpitzer T, Ganel A, Engelberg S. Surgery for synovial chondromatosis: 26 cases followed up for 6 years. Acta Orthop Scand 1990;61:567-9.

17. McCarthy EF, Dorfman HD. Primary synovial chondromatosis: an ultrastructural study. Clin Orthop 1982;168:178-86.

18. Morrey BF. Functional evaluation of the elbow. In Morrey BF, ed. The elbow and its disorders. 2nd ed. Philadelphia: WB Saunders; 1993.

19. Jones JR, Evans DM, Kaushik A. Synovial chondromatosis presenting with peripheral nerve compression: a report of two cases. $J$ Hand Surg [Br] 1987;12:25-7.

20. Ono H, Yajima H, Fukui A, Tamai S. Locking wrist with synovial chondromatosis: report of two cases. $J$ Hand Surg Am 1994;19:797-9.

21. Bell MS. Loose bodies in the elbow. Br J Surg 1975;62:921-4.

22. Fahmy NR, Noble J. Ulnar nerve palsy as a complication of synovial chondromatosis of the elbow. Hand 1981;13:308-10.

23. Maurice H, Crone M, Watt I. Synovial chondromatosis. J Bone Joint Surg [Br] 1988;70-B:807-11.

24. Davis RI, Hamilton A, Biggart JD. Primary synovial chondromatosis: a clinicopathologic review and assessment of malignant potential. Hum Pathol 1998;29:683-8

25. Campeau NG, Lewis BD. Ultrasound appearance of synovial osteochondromatosis of the shoulder. Mayo Clin Proc 1998;73:1079-81.

26. Rao JP, Spingola C, Mastromonaco E, Villacin A. Synovial osteochondromatosis: computerized axial tomography, frozen section, and arthrography in diagnosis and management. Orthop Rev 1986;15:245-8

27. McIvor RR, King D. Synoviale chondromatose. Orthopaede 1988;17:233-44.

28. Jeffreys TE. Synovial chondromatosis. J Bone Joint Surg $[\mathrm{Br}]$ 1967;49-B:530-4. 